\title{
EDITORIAL
}

\section{OR and competitive tendering}

A great many business transactlons, including an increasing number in the public sector, involve contracts for the supply of a product or service which are awarded by competitive tender. Indeed, for the majority of firms this is the main way in which sales revenue is obtained. The usual format is that fixed-price bids are invited for a specifled plece of work, and the contractor submitting the lowest bid (other things being equal) is awarded the contract. On this basis, the client's decision is straightforward, but the contractor's decision of what price to bid is more tricky. Bidding low in the face of competition Increases the chance of winning the contract, but it may compromise profitability. However, bldding at a level which ensures a good return Increases the chance that a competitor will submit a lower bid and win the contract.

Operational researchers have been aware of this problem for more than 30 years and characteristically a variety of mathematical models to help contractors determine the optimum bld have been developed. The basic model involves determining the bid $b$ which maximizes expected profit $E(b)$ where

$$
\begin{aligned}
E(b)= & (b-c) P(b) \\
\text { with } b= & \text { bid price } \\
c= & \text { estimated cost of performing the } \\
& \text { contract } \\
P(b)= & \text { probability of winning with bid } b
\end{aligned}
$$

The problem then becomes one of determining $c$ with appropriate preclsion and estimating $P(b)$ from any current knowledge and experience of competitors' bldding on earller contracts. A wide variety of competitive bidding situatlons have been analysed In the quantitative Ilterature, providing many insights into the nature of profltable bidding strategles. However, use of these approaches does not seem to be particularly widespread, even in very large organizations which obtain most of their business via competitive contracts.

There are a number of likely reasons for this. Many managers would argue that quantitative models cannot be reliable because their use of historical data requires the unrealistic assumption that competitors will exhibit the same bidding behaviour as they have in the past. Others may argue that obtaining the information required by quantitative models is too difficult, too expensive, or Impossible. Such arguments may reflect a lack of understanding, or organization and effort in collecting, collating and interpreting relevant information. This in turn suggests either a failure on the part of OR practlioners to convince managers that such efforts are worthwhile, or a fallure on the part of theorists to convince practitioners that theoretical approaches are a practical proposition. Certainly, collecting sufficient data for quantitative analyses may take years, but the pay-offs could be substantial.
There Is, however, a wider potential role for OR in helping organizations to develop a more coherent, systematic and profitable approach to bid preparation. This is apparent when one considers some of the additional complexities and concerns involved in pricing contracts.

Often, a belief that the lowest price tendered will win the contract is worth investlgating more closely. Amblgulties or uncertalnty in speclfications can mean that simple comparison of competing tenders on the basis of a bottom-line price may be inequitable or misleading because like is not belng compared with like. In these circumstances it can be important for contractors to know how sophisticated a buyer's comparison of competing tenders is likely to be.

A common difficulty is assessment of the overall cost of complex quotations involving piece-rates for uncertain levels of work. This gives a contractor opportunities to price high items the buyer is thought to have underestimated in quantity and price low items the buyer is thought to have overestimated. The effect is either to increase the profitability of a contract without apparently increasing total price, or to reduce the apparent total price (and thereby increase the chance of winning) without reducing profitability if the contract is won. In recognition of this problem, some contract buyers may employ detailed researchers (see, for example, Williamson, 1985). Many will not, and contracts may be awarded on a partlal comparison of competing tenders. For example, one organization habitually compared servicing contracts on the basis of prices tendered for regular servicing and ignored the prices tendered for emergency callouts - a potentlally expensive practice!

Equally problematic are contracts where the product or service specification Is ambiguous or lacking in detall. If tenders are to be assessed in a naive way on bottomline price alone, it may be disadvantageous to seek clarification of specifications which lead to higher costs and hence a higher bid. Competing contractors who fail to seek similar clarificatlons may submit lower tenders and, if successful, will subsequently charge extra for the "additional" work required by the buyer. On the other hand, if the buyer is specification-conscious, it may be worth investigating alternative specifications which offer lower cost or better quality.

Quite apart from these concerns, awarding contracts on the basis of the lowest "fixed"-price bid can be unsatisfactory both for the buyer and for the winning contractor, because of the effect known as the "winner's curse". When a fixed-price contract is awarded on the basis of a competitlve tender, research suggests that the contractor who accidentally or deliberately underestimates the contract cost is most llkely to get the work. This can be a serious problem for both parties if 
performance specifications are not comprehensive, clear and legally enforceable, if uncertainty is important (as in, for example, ground conditions in a tunnelling contract), or if the expertise and financial security of the contractor are not beyond question. Such conditions are common in large engineering projects, and increase the likelihood that the winning contractor will encounter significant financial risks. Attempts to mitigate losses can result in corner-cutting and a propensity to press for additional payments from the buyer. Neither outcome is in the buyer's interest.

One remedy is to carry out an analysis of project risks prior to tendering, in order to draw up a contract which allocates risks appropriately between contracting parties. This can benefit both parties. Despite a certain amount of theoretical work on risk-sharing, this is still an area which is wide open for development by OR practitioners.

An additional and perhaps more common remedy is to take on board one of Deming's 14 points for total quality management, and end the practice of awarding business solely on the basis of the price tag. For repetitive business this can mean developing co-operative, longterm relationships with a selected number of contractors who can then be relied upon to deliver on both cost and quality. For occasional or one-off contracts, this implies concern with a number of non-price criteria, such as the reputation, size, location and special skills of contractors, previous experiences with contractors, proposed payment schedules, and so on. If any of these factors are likely to influence the choice of contractor in a given situation, then contractors should try to take these into account in preparing their bids. As a minimum, contractors ought to identify those factors a buyer values and those to which a buyer is indifferent. Sometimes it may be worthwhile for a contractor actively to promote the value of a particular non-price factor(s) that can be offered by the contractor. Often it is possible to obtain information from the buyer concerning the relative importance and value placed on the various non-price criteria operating in a given situation or for particular types of contract work. Such information can be more readily forthcoming than many companies might think. The trouble is that all too often the personnel from contracting firms who make the most contact with buyers are not charged with obtaining this information, or else do not pass it on to those involved in determining bid prices.

Other factors likely to influence the size of a bid might be the size or prestige of the associated contract and the availability of the contractor's resources. Contracts may not be equally attractive when interdependencies with other ventures or long-term objectives are taken into account. Adopting a long-term, strategic view raises further concerns about an organization's contracting activities, related primarily to the need for an adequate long-term return on capital. Many companies do not consider this issue at all, and adopt a pragmatic approach which often amounts to bidding for and trying to win as much business as possible. Bids for mainstream business are based on marginal costings, mark-ups are pared in an ad hoc way, and the true profitability of recently-completed contracts is not determined. In many situations the cost of preparing bids is significant, yet little attention is paid to how much effort should be expended on bidding for new contracts, and to the question of what proportion of tenders turn into firm contracts. Very different strategies (and costs) are implied for a firm which tenders for a small number of contracts but succeeds in winning a large proportion of them, and for a firm which tenders for a large number of contracts but wins only a small proportion of them. How many firms even collect this information on a regular basis?

Here is a major opportunity for OR: to put competitive tendering within client organizations on a more systematic and profitable basis. Quantitative models, aimed at estimating the optimum bid price for a given contract, may meet with a high degree of scepticism, and in any case are not a first priority. More important is the co-ordination of all relevant expertise in contracting organizations. All relevant information needs to be captured and pooled. Both quantitative and qualitative rationales for pricing individual tenders need to be formally recorded, and the ongoing performance of bidding activity and completed contracts continuously monitored.

\section{STEPHEN WARD}

\section{For the interested reader}

Chapman, C.B., Ward, S.C. and Curtis, B. (1988): "Risk theory for contracting", Construction Contract Policy - Improved Procedures and Practice (proceedings of a conference organized by the Centre for Construction Law and Project Management, King's College, London).

Ward, S.C. and Chapman, C.B. (1988): "Developing competitive bids A framework for information processing", J. Opl Res. Soc. Vol. 39, No. 2, pp. 123-134.

Williamson, S.L. (1985): "OR involvement in the allocation of a major contract", J. Opl Res. Soc. Vol. 36, No. 8, pp. 731-736. 